\title{
Throat Tightening
}

National Cancer Institute

\section{Source}

National Cancer Institute. Throat Tightening. NCI Thesaurus. Code C122578.

The sensation of constriction or contraction in the throat area. 